\title{
"By their fruits you will recognize them": notes dedicated to Professor Karol Latowski - the prominent Polish botanist
}

\author{
Antonina P. Ilyinska ${ }^{1}$, Andriy V. Yena², Sergei L. Mosyakin ${ }^{1}$, \\ Viera V. Protopopova ${ }^{1} \&$ Myroslav V. Shevera $^{1 * *}$
}

${ }^{1}$ M. G. Kholodny Institute of Botany, National Academy of Sciences of Ukraine, Tereschenkivska 2, Kiev, 01601, Ukraine

${ }^{2}$ Crimean Agrotechnological University, vill. Agrarne, Simferopol, 95492

** corresponding author (e-mail: shevera@mail.ru)

Real science is international by its very nature. It is especially true for botany, which requires combined efforts and good communication between researchers from different countries. The fascinating plant world of Ukraine was studied by many scientists from various lands and of various backgrounds. There were brilliant researchers of Ukrainian, Russian, Polish, Austrian, German, Romanian, Hungarian, Czech and some other origins. All are remembered and valued in the presentday Ukraine.

In particular, we greatly value the considerable contribution made to Ukrainian botany by Polish researchers (or, at least, those of Polish origin and background). The names of such outstanding botanists as: Antoni Andrzejowski, Hugo Zapałowicz, Józef Paczoski, Stanisław Kulczyński, Bogumił Pawłowski and Władysław Szafer, are well known among and respected by the Ukrainian botanical community. They contributed to a better knowledge of our flora in a wide geographical scope: from western regions of Ukraine, such as the Carpathians and adjacent areas, south to the Steppe zone and Crimea. We are happy that these noble traditions are continued by contemporary researchers of our two countries. This friendly and productive collaboration is pursued by many, including the hero of our notes, Professor Karol Latowski.

Professor K. Latowski is well known as a botanist skilled in plant systematics and morphology, floristics,

* (Mattew 7: 16) phytosociology and history of science. He is also a man of refined culture, an open-hearted and magnetic personality. Here we would like to emphasize only two of many sides of his activity that he shared with his Ukrainian colleagues.

Among others, Prof. K. Latowski clearly demonstrated the benefits of using anatomic characters of fruits and seeds in the systematics of Brassicaceae. In the period from 1975-1980, he undertook a number of fundamental anatomic and taxonomic studies of fruits and seeds in the genus Lepidium L., involving data collected from many herbaria in Europe, including Poland, Russia and Bulgaria. Distribution maps arranged by him remain valid until now, especially those drawn for the first time for L. apetalum Will. and L. latifolium L. in the Asian part of their range.

In general, K. Latowski revealed or re-evaluated the taxonomic importance and implications of some morphological and anatomical characters of fruits and seeds (27 and 11, respectively) through 13000 measurements done by him personally. In order to process the data obtained, he was among the first to apply methods of numerical taxonomy. He also made comprehensive carpological descriptions for each species and subspecies studied, selecting diagnostic characters and preparing unconventional keys for recognizing those taxa. Based on these studies, K. Latowski discovered or outlined two morphological types of fruits corresponding to two geographic and evolutionary centers of the genus Lepidium comprising Mediterranean and American-Asian regions. 
Following the polytypic species concept in the interpretation of anatomical characters of fruits and seeds in the Lepidium genus, Prof. K. Latowski showed that morpho-ecological salinity-resistant races $-L$. borysthenicum Kleopow and L. pumilum Boiss. et Balansa (accepted earlier as distinct morphological and ecological units) - were closely related and could be treated within L. cartilagineum (J. Mayer) Thell. s.l. Since then, this decision was accepted by nearly all specialists in Brassicaceae. Latowski's subdivision of the genus Lepidium into three subgenera, Lepidium, Cardaria and Lepia, was, in general, supported by modern molecular phylogenetic results. In addition, Karol Latowski was the first to find L. pinnatifidum Ledeb. in Ukraine, and this locality still remains the only known in our country. Professor K. Latowski shared with the global scientific community his deep monographic studies on Lepidium as well as Erysimum L., thus, promoting further development of our better understanding of evolution and taxonomy of Brassicaceae. In his home country, he applied results of his investigations in compiling relevant data for "Flora Polski" (1985). Apart from preparing specific keys, he also described diversity of forms within each species occurring on the studied territory and supplied texts with data concerning their chromosome number, ecology and chorology and with beautiful drawings.

For Ukrainian botanists, K. Latowski's selfless activity aimed at the preservation of rich scientific heritage of J. Paczoski is of prime importance. K. Latowski was among those who initiated the reburial of Paczoski's remains at the Great Poland Citizens Memorial Cemetery Park in Poznan, established the hall in memory of J. Paczoski in the Adam Mickiewicz University and mounted a memorial plate in the University Botanical Garden. Due to continued efforts of Prof. K. Latowski and the support of Adam Mickiewicz University, the second volume of the Khersonian Flora by J. Paczoski was published in 2008. This outstanding work, which contains unique data on systematics, biology, ecology and distribution of 1049 (and additional 307 non-numbered!) species of vascular plants, brought its invaluable scientific and historical message 80 years after the first volume was printed.

Another of K. Latowski's botanical and humanitarian initiative is promotion of the method of herbarization (known as "Polish Press") proposed by a Polish botanist, Józef Mądalski. Despite the parsimonious character of the method, work convenience and high quality of specimens obtained, the "Polish Press" remained undeservedly little known in many countries, so due to Prof. K. Latowski, this way of herbarization is becoming more and more familiar to professional collectors, students and amateurs throughout the world, and, now, especially in Ukraine.

Members of the Ukrainian Botanical Society (of which Prof. Karol Latowski is an elected Honorary Member) and the whole plant science community of Ukraine sincerely express their deep gratitude to Prof. Latowski for his great contribution to our beloved science, its history, and traditional friendship between Poland and Ukraine and our peoples. He visited Ukraine several times in different years, participated in various scientific conferences, like the Congresses of UBS, conferences in memory of J. Paczoski and also, traditionally, in the international conference Anthropization and environment of rural settlementts. Flora and vegetation. Professor K. Latowski is always a welcome guest not only at formal presentations, as an exciting speaker or dramatic polemist, but also out of sessions and during after-congress meetings, as a knowledgeable expert, interesting companion, and just a very bright and kind personality. 